\title{
Descriptions of two new species of Neuroterus Hartig from China (Hymenoptera: Cynipidae)
}

\author{
Juli Pujade-Villar, Yiping Wang*, Zhiwei Liu, Rui Guo
}

\begin{abstract}
Pujade-Villar, J., Wang, Y., Liu, Z. \& Guo, R. 2016: Descriptions of two new species of Neuroterus Hartig from China (Hymenoptera: Cynipidae). - Entomol. Fennica 27: 23-32.

Two morphologically unusual new species of Neuroterus Hartig, Neuroterus sculpturatus Pujade-Villar \& Wang sp. n. and N. abdominalis Pujade-Villar \& Wang sp. n., are described from China. Data about galls, distribution and biology of the new species are included. Taxonomic problems concerning some of the Palaearctic Neuroterus species, including the species described here, are also commented.
\end{abstract}

J. Pujade-Villar, Department of Animal Biology, Barcelona University, Barcelona 08028, Spain; E-mail: jpujade@ub.edu

Y. Wang (*corresponding author), College of Forest and Biotechnology, Zhejiang Agricultural and Forestry University, Lin'an 311300, China; E-mail: ypwang123@gmail.com,wyp@zafu.edu.cn

Z. Liu, Department of Biological Sciences, Eastern Illinois University, Charleston,61029, Illinois, U.S.A.; E-mail: zliu@eiu.edu

R. Guo, Administration Bureau of Zhejiang Qingliangfeng National Nature Reserve,Lin'an 311300,China; E-mail: guruwos@126.com

Received 25 May 2015, accepted 8 October 2015

\section{Introduction}

Until recently, the genus Neuroterus was considered to comprise approximately 100 species widely distributed throughout the Holarctic region (Stone et al. 2002). These 100 species were classified into 6 subgenera by Kinsey in his monographic treatment of the genus (Kinsey 1923). However, the subdivision of Kinsey has become obsolete: some of the subgenera are hard to distinguish morphologically and the genus has been considerably redefined. Trichagalma Mayr, a genus previously synonymized with Neuroterus by Abe (2006), was re-established to include Trichagalma serratae (Ashmead) and Trichagalma acutissimae (Monzen) (Melika et al.
2010); Cerroneuroterus Melika \& Pujade-Villar was erected to include four new European species, i.e., C. aggregatus (Wachtl), C. cerrifloralis (Müllner), C. obtectus (Wachtl) and C. lanuginosus (Giraud) (Melika et al. 2010); Pseudoneuroterus Kinsey, originally treated as a subgenus of Neuroterus, was elevated to the generic status to include P. macropterus (Hartig) (PujadeVillar et al. 2004) and the subsequently added $P$. saliens (Kollar) (Melika et al. 2010); finally, the genus Latuspina Monzen, originally described as a subgenus of Neuroterus, was also raised to the generic status to include the single Japanese species, L. stirps (Monzen). Many new species have subsequently been described to the aforementioned genera (Melika 2006, Melika et al. 2010, 
Pujade-Villar \& Wang 2012, Tang et al. 2012). Furthermore, the recently described genus $\mathrm{Cyclo-}$ neuroterus Melika \& Tang, with five known species from Taiwan, obviously belongs to the Neuroterus complex (Tang et al. 2011). The redefined Neuroterus Hartig, 1840 is currently represented by 84 species, including 6 from the Western Palaearctic area (Melika et al. 2010), 14 in the eastern Palaeactic - 6 of them are of uncertain systematic position - (Abe et al. 2007, Melika et al. 2010), 52 from North America (Burks 1979, Melika \& Abrahamson 1997, 2002), and 8 from Mexico (Pujade-Villar et al. 2009, Pujade-Villar \& Ferrer-Suay 2015).

The genus as previously defined consists of species forming galls on oaks (Quercus) in three sections: Cerris, Quercus s.s. (the white oaks), and Protobalanus (the intermediate oaks) (Stone et al. 2002), but the redefined Neuroterus appears to be relatively more specific regarding its host association; all species currently included in Neuroterus are associated with white oaks (section Quercus s.s.), the only exception is $N$. chrysolepis Lyon from California, USA, which is associated with $Q$. chrysolepis in the section Protobalanus. No species of Neuroterus is associated with the diverse North American red oaks (section Lobatae).

The alternating asexual and sexual generations are poorly known for the genus, except for the Western Palaearctic species (Pujade-Villar et al. 2001). The galls of Neuroterus species are usually structurally more primitive than those of other Cynipini genera and lack the highly specialized tissues and tissue layers of the other galls (Melika 2006).

Many of these species, especially those from Nearctic and the Eastern Palaearctic regions need revision (Melika et al. 2010). Abe et al. (2007) listed the Neuroterus species of the Eastern Palaearctic with taxonomic comments and indicated that some of the species were in need of revision.

As noticed by Melika et al. (2010), several species of the genus have distinctive morphological peculiarities - i. e. N. anthracinus (Curtis) and $N$. politus Hartig from Western Palaearctic region. In the present study, we describe two additional morphologically divergent new species from China and discuss their inclusion in Neuroterus.

\section{Materials and methods}

Throughout the paper, we followed the terminology used in Liljeblad and Ronquist (1998) and Melika (2006) for structural morphology, Ronquist and Nordlander (1989) for abbreviations on forewing venation, and Harris (1979) for cuticular surface sculpture. Measurements and abbreviations used are:

- F1-F12, first and subsequent flagellomeres

- POL, post-ocellar distance, the distance between the inner margins of the posterior ocelli

- OOL, ocellar-ocular distance, the distance from the outer margin of the posterior ocellus to the inner margin of the compound eye

- LOL, the distance between lateral and frontal ocelli

- The width of the forewing radial cell was measured from the margin of the wing to the Rs vein.

Descriptions and measurements were made under a Leica MZ 12.5 stereomicroscope (Wetzlar, Germany), and photos were taken by a digital camera (Q-Imaging, Micropublisher 3.3 RTV) attached to a Leica MZ APO stereomicroscope (Wetzlar, Germany) and stacked using Synoptics AutoMontage version 5.0 software. The field-emission gun environmental scanning electron microscope (FEI Quanta 200 ESEM, Barcelona University) was used for high-resolution imaging without gold-coating.

Type specimens are deposited in the Hymenoptera Collection of Zhejiang Agricultural and Forest University, Lin'an, China (ZAFU) and the University of Barcelona (UB) as detailed in the species descriptions.

\section{Descriptions of two new species of Neuroterus}

\subsection{Neuroterus sculpturatus Pujade-Villar \& Wang sp. n. (Fig. 1, 2e-i)}

Type material. Holotype $\bigcirc_{\text {: }}$ China, Shaanxi, Houzhenzi $\left(107^{\circ} 47^{\prime} \mathrm{E}, 33^{\circ} 50^{\prime} \mathrm{N}\right)$, galls collected from Quercus variabilis Blume on 17.V.2011, and adult wasp emerged on 5.VI.2011, Guo Rui 


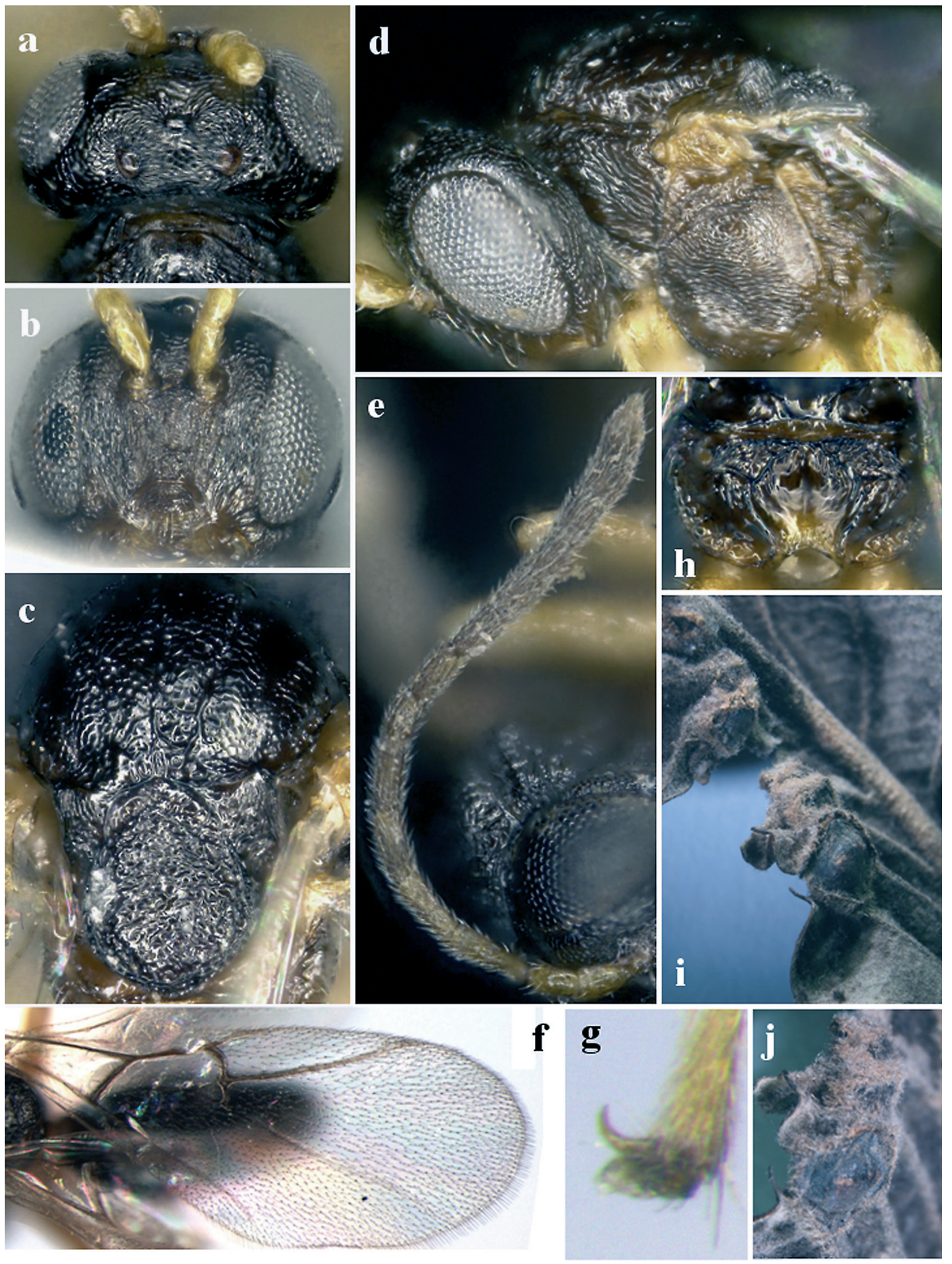

Fig. 1. Neuroterus sculpturatus sp. n. -a. Head, dorsal view. - b. Head, frontal view. - c. Mesosoma, dorsal view. - d. Head and mesosoma, lateral view. - e. Female antenna. - f. Forewing. - g. Tarsal claws. - h. Propodeum. $-\mathrm{i}-\mathrm{j}$. Gall. 
leg. Paratypes: $1+1 \hat{\partial}$, same data as holotype. Holotype and paratype $\widehat{\sigma}$ deposited in ZAFU; $q$ paratype deposited in UB (JP-V collection).

Diagnosis. The new species differs from all known species of Neuroterus in having strong sculpture on mesosoma including mesopleuron.

Description, sexual generation.

Length. Female: $2.0 \mathrm{~mm}(\mathrm{n}=2)$; male: $1.8 \mathrm{~mm}$ $(\mathrm{n}=1)$.

Colour. Head yellowish brown or dark brown; antennal scape and pedicel pale yellow, flagellomeres yellowish brown (male antennae basally pale yellow and apically dark yellow); mesosoma dark brown, darker in some areas; mandibles pale yellow with dark brown tips, maxillae and labium yellow; legs dark yellow (yellowish in males); metasoma black; hypopygium pale red; wing veins brown.

Head (Figs 1a-b, 2h). Head subquadrate in frontal view, around 1.3-1.4 times as broad as high, distinctly broader than mesosoma in frontal view, with sparse short white setae, and 1.9-2.0 times as wide as long in dorsal view. Lower face without lateral striae radiating from clypeus while medially coriaceous; area below antennal sockets with a few interrupted striae. Transfacial distance equal to height of compound eye. Inner margins of compound eyes parallel. Distance between inner margin of compound eye and antennal socket equal to diameter of antennal socket, and 1.8-1.9 times the distance between antennal sockets. Clypeus conspicuous, anterior tentorial pits distinct but small; epistomal sulcus and clypeo-pleurostomal lines distinct. Malar space quite small and with short striae, extending to eye; malar sulcus only traceable. POL: OOL: $\mathrm{LOL}=7: 4: 4$ (in males $5: 3: 3$ ), diameter of lateral ocellus 2.5 in the same scale for POL (2.0 in males). Gena coriaceous and shiny, not broadened behind compound eye. Frons, vertex, and occiput uniformly coriaceous and shiny.

Antenna. Female (Fig. 1e): with 12 flagellomeres, slightly shorter than body length: pedicel 2.5 times as long as broad; F1 1.1 times longer than F2, 1.8 times longer than pedicel; F3 to F6 of equal length, F8 to F10 equal in length, F4 and subsequent flagellomeres each broader than the proceeding one; $F 12$ around 1.4 times longer than F11; antennal formula is: $6: 5: 9: 8: 6: 6: 6: 6: 5.5$ : 5: 5: 5: 7; placodeal sensillas present from F4.
Male (Fig. 2e-f): with 15 segments, first flagellomere incised and apically expanded; antennal formula: 4.5:4:9: 8: 7: 7: 7: 5:5:5:5:5:4.5:4.5:6.

Mesosoma (Figs 1c-d, h, 2g, i). Mesoscutum 1.3 times as long as broad in dorsal view. Pronotum strongly coriaceous and laterally strongly striate. Mesoscutum strongly coriaceous in most of its surface and partially reticulate, with a few white setae; slightly longer than maximum width (measured across mesoscutum between tegulae at anterior tip). Notauli percurrent, reaching pronotum, impressed in its entire length; parapsidal lines present, median mesoscutal impression present, weakly impressed but extending almost to entire length of mesoscutum; anterior mesoscutal parallel lines absent; parascutal carina usually broad, extending to the point where notaulus reaches pronotum. Mesoscutellum slightly longer than wide, quadrangular, laterally uniformly covered by strong rugose sculpture and medially strongly coriaceous, slightly overhanging metanotum. Transscutal articulation absent; scutellar foveae absent but transversal scutellar depression present with weak rugae inside and not separated by a median carina. Mesopleuron and speculum strongly coriaceous, with thin but distinct longitudinal striation on lower mesopleuron. Dorsal axillar area reticulate, with white setae; mesopleural triangle rugose and alutaceous; lateral axillar area rugose, with few setae; metanotal trough smooth and shiny; subaxillular bar smooth, shiny; metapleural sulcus reaching mesopleuron at half of its height. Metascutellum delicately coriaceous; central propodeal area broad, smooth, shiny, with some interrupted longitudinal rugae; lateral propodeal carinae strongly bent outwards in the middle; lateral propodeal area smooth and shiny, without setae.

Legs (Fig. 1g). Tarsal claws simple, without basal lobe.

Forewing (Fig. 1f). Forewing longer than body, hyaline, with distinct long dense cilia on margin; radial cell open and long, 3.3-3.4 times as long as wide; R1 reaching wing margin and continuing along margin for a short distance; Rs slightly curved, nearly reaching wing margin; areolet closed, large, and triangular; vein Rs $+\mathrm{M}$ reaching toward basalis at lower one third, but not reaching basalis.

Metasoma. Female: slightly shorter than head 


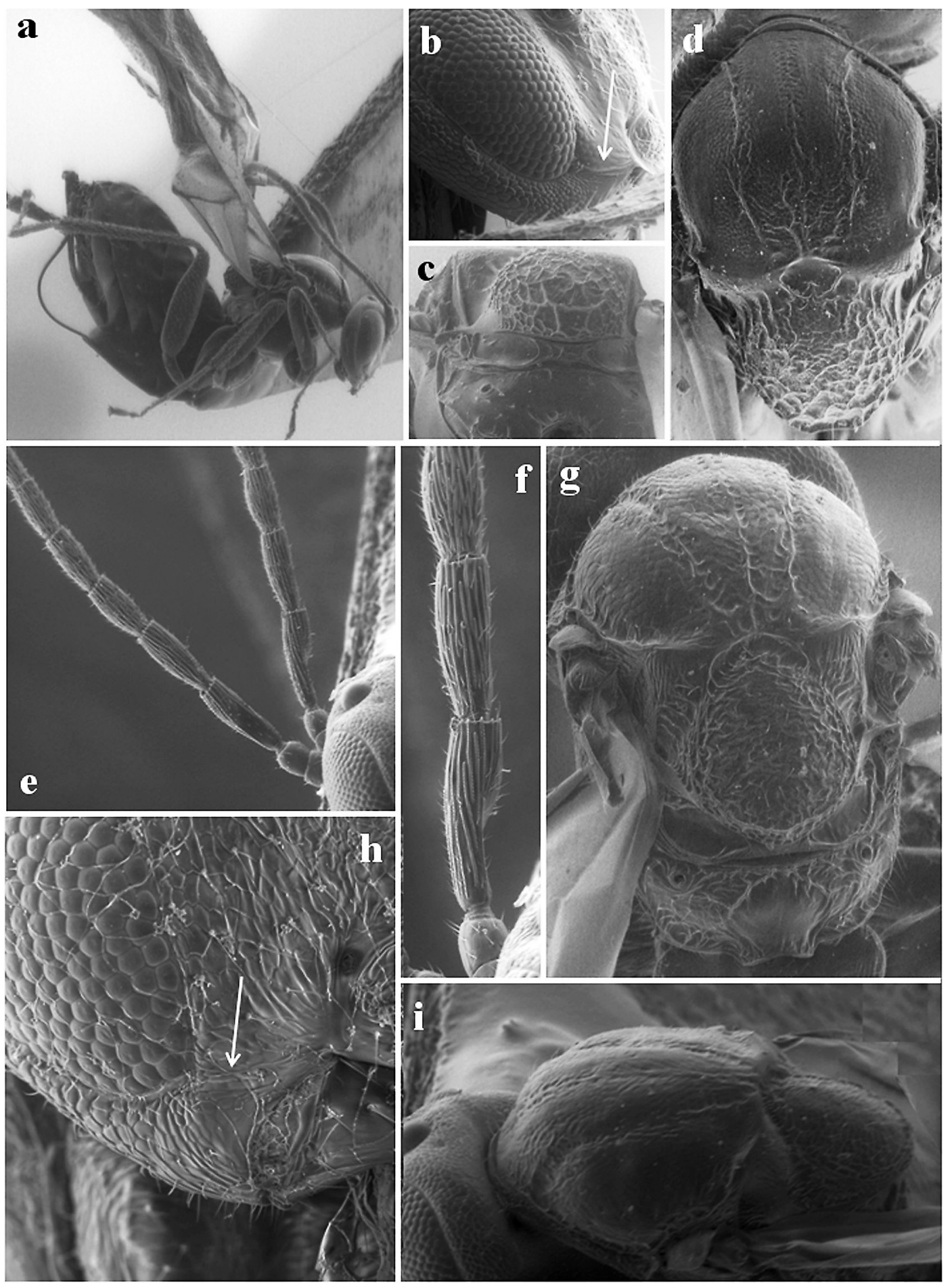

Fig. 2. Neuroterus abdominalis sp. n. (a-d) and N. sculpturatus sp. n. (e-i). - a. Body, general view. - b. Head, lateral view indicating malar sulcus. - c. Propodeum, dorsal view. - d. Mesosoma, dorsal view. - e. Basal antenna, male. $-\mathrm{f}$. First flagellomere, male. $-\mathrm{g}$. Mesosoma and propodeum, dorsal view. $-\mathrm{h}$. Malar area indicating malar sulcus. - i. Mesoscutum, dorso-lateral view. 
plus mesosoma, higher than long in lateral view; $2^{\text {nd }}$ metasomal tergite occupying $1 / 3$ of the length of metasoma in dorsal view, smooth and shiny, with a few white setae laterally, all subsequent tergites smooth and shiny without setae; prominent part of ventral spine of hypopygium short, pointed, 1.0-2.0 times as long as broad from ventral view, with long sparse white subapical setae, extending far beyond apex of spine. Male: distinctly shorter than head plus mesosoma.

Etymology. Latin, suggestive of the strong sculpture of mesosoma including mesopleuron.

Distribution. China (Shaanxi).

Gall (Fig 1i-j). Galls are formed in clusters on leaf edge, with 3-5 galls in each cluster, and individual galls are usually like soybeans in size and shape, $0.5-1.0 \mathrm{~cm}$ in diameter. Young galls are integral and pale green in colour, becoming dark green later, and turning to brown or dark brown as they mature, when they will also become detachable. Individual galls are hollow, with a tough and thin woody wall $3.0-4.0 \mathrm{~mm}$ thick; the interior space contains a single, free larval chamber.

Biology. All galls were found on leaves of Quercus variabilis belonging to the Cerris section. In the laboratory, adults emerged in early June from galls collected in mid-May.

\subsection{Neuroterus abdominalis Pujade-Villar \& Wang sp. n. (Figs 2a-d, 3)}

Type material. Holotype + : China, Zhejiang, West Tianmu Mountain (119²7' E, 30¹9’ N), gall collected from Quercus acutissima Carruth. on 22.IX.2010, and adult wasp emerged on 5.III. 2011, Guo Rui leg. Paratypes: $59+$, same data as holotype. Holotype and $3 q \circ$ paratypes deposited in ZAFU, 2 우 paratypes deposited in UB (JP-V collection).

Diagnosis. The new species is similar to $N$. sculpturatus sp. n. in the sculpture of mesoscutum, but it differs from the latter in having an almost smooth mesopleuron. In addition, the metasoma of these species is unusually large compared with the latter and all other species in the genus.

Description, asexual generation.

Length. Female: 2.2-2.4 mm $(n=6)$; male: unknown.

Colour. Head and mesosoma dark brown; me- tasoma blackish to dark brown; clypeus, mandibles, palpi, labialis and maxillaris light yellow; legs uniformly dark yellow; antennae uniformly brown.

Head (Figs 2b, 3a-b). Head subquadrate in frontal view, around 1.3-1.4 times as broad as high and distinctly broader than mesosoma, with sparse short white setae, and about 2.8-2.9 times as wide as long in dorsal view. Lower face shiny, alutaceous, without thin lateral carinae radiating from clypeus. Clypeus conspicuous, anterior tentorial pits distinct but small; epistomal sulcus and clypeo-pleurostomal lines indistinct. Malar space 0.3 times as long as height of compound eye; malar sulcus traceable; transfacial distance 1.3 times as long as height of eye. Inner margins of compound eyes parallel. Distance between inner margin of compound eye and antennal socket 1.3 times as long as diameter of antennal socket, and 1.1 times as long as distance between antennal sockets. POL: OOL: $\mathrm{LOL}=15: 10: 7$, diameter of lateral ocellus 3.0 to the same scale. Gena alutaceous and shiny, not broadened behind compound eye. Frons, vertex and occiput uniformly coriaceous and shiny.

Antenna (Fig. 1f). Antenna 14-segmented, pedicel nearly as long as its broad; F1 1.3 times longer than F2, 2.2 times as long as pedicel; F3 to $\mathrm{F} 5$ equals in length, $\mathrm{F} 4$ and each subsequent flagellomere broader than the proceeding one; F11 around 1.1 times longer than F10; antennal formula: 11: 9: 20: 15: 14: 14: 14: 13: 12: 10: 10: 9: 10. Placodeal sensillas present from F4.

Mesosoma (Figs 2c-d, 3c-d). Mesosoma 1.1 times as long as high in lateral view. Pronotum smooth, laterally with weak transverse carinae. Anterolateral mesoscutum strongly coriaceous to alutaceous, with somewhat medial and posterior rugulose sculpture; maximum width slightly broader than long (measured between tegulae at anterior tips). Notauli percurrent, but superficial; parapsidal lines present, median mesoscutal impression short, anterior parallel lines indicated by glabrous stripes. Mesoscutellum slightly broader or as broad as long, quadrangular, with brownish setae denser than on mesoscutum, uniformly covered by strong rugose sculpture at the laterals and strongly coriaceous in the medial region, slightly overhanging metanotum. Transscutal articulation absent; scutellar foveae absent but transversal 


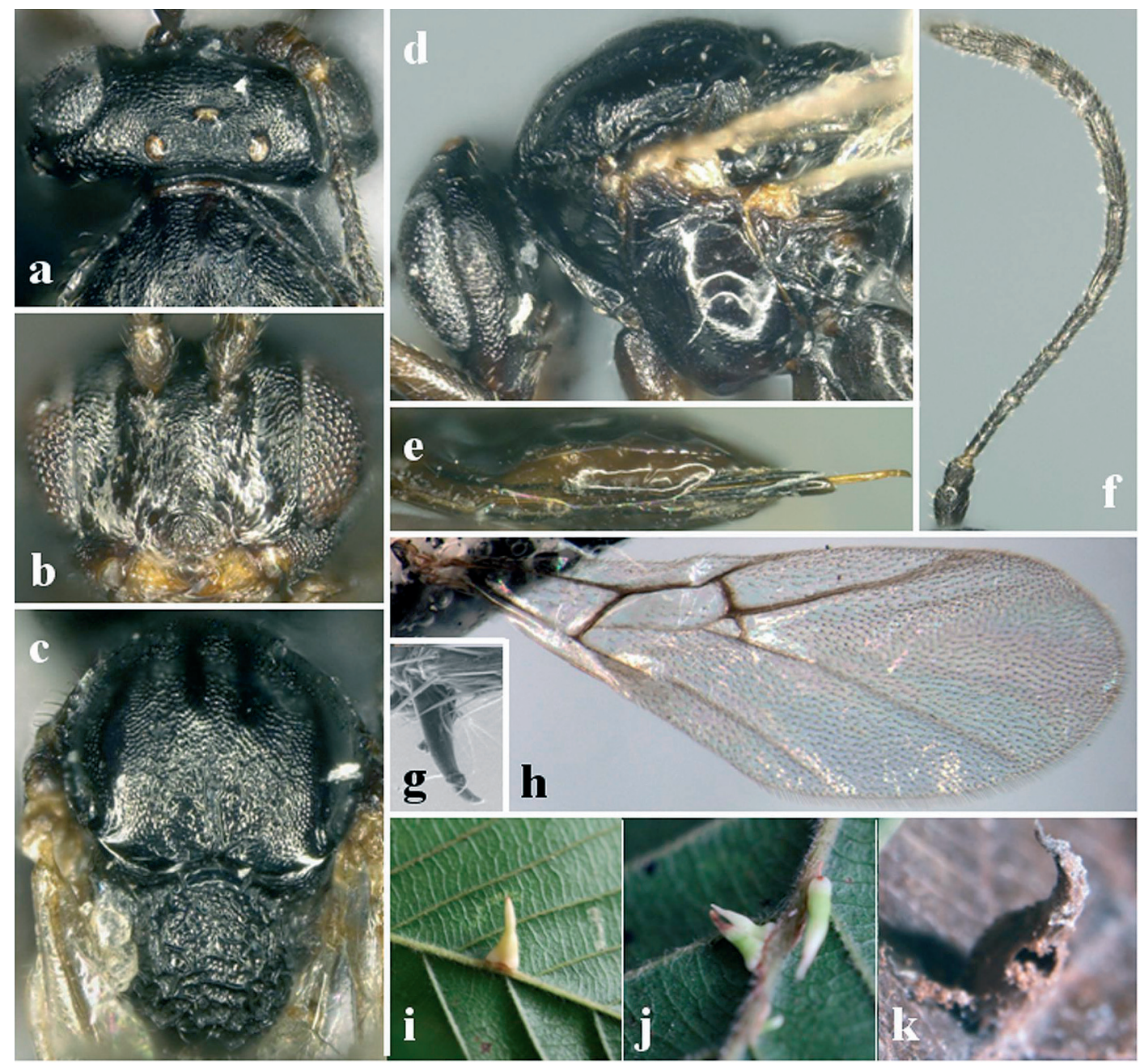

Fig. 3. Neuroterus abdominalis sp. n. - a. Head, dorsal view. - b. Head, frontal view. - c. Mesosoma, dorsal view. - d. Head and mesosoma, lateral view. - e. Female metasoma, ventral view. - f. Female antenna. - g. Tarsal claws. - h. Forewing. $-\mathrm{i}-\mathrm{k}$. Gall.

scutellar depression present not separated by median carina, smooth inside. Mesopleuron and speculum shiny, slightly alutaceous, with some smooth areas. Dorsal axillar area smooth, with white setae; mesopleural triangle alutaceous; lateral axillar area smooth, with few setae; subaxillular bar smooth and shiny; metapleural sulcus reaching mesopleuron at half of its height. Metascutellum delicately coriaceous, metanotal trough smooth, shiny, with few short white setae; central propodeal area smooth and shiny, with some interrupted carinae basally; lateral propodeal carinae absent; lateral propodeal area glabrous.
Legs (Fig. 3g). Tarsal claws simple and without basal lobe.

Forewing (Fig. 3h). Forewing margin ciliated and relatively ventrally longer; radial cell open, 3.7-3.8 times as long as wide; areolet conspicuous; vein Rs only lightly curved apically, not reaching the margin of wing as vein $\mathrm{R} 1$; vein $\mathrm{R} 1+\mathrm{Sc}$ hardly interrupted before reaching basal vein.

Metasoma (Figs 2a, 3e). Very long, 1.5 times as long as head plus mesosoma, slightly shorter than 2.0 times as long as higher in lateral view; with sparse short setae anterolaterally, and smooth and shiny; prominent part of ventral spine 
of hypopygium short and with sparse short setae apically.

Etymology. Latin, suggestive of length and shape of metasoma.

Distribution. China (Zhejiang).

Gall (Fig 3i-k). Ox horn-shaped, monothalmous galls are formed on the main vein or lateral veins of leaf. The galls are $1.5-2.0 \mathrm{~cm}$ long, milk white young galls turning to yellowish green and hollow with a hard and thin woody wall 2.0 $2.5 \mathrm{~mm}$ thick when they become mature, and inside the interior space contains a single and free larval chamber.

Biology. All galls were collected on Quercus acutissima belonging to the Cerris section. In the laboratory, adults emerged in early March from galls collected in the previous September.

\section{Discussion}

The numerous systematic studies on Neuroterus and the newly recognized and obviously closely related genera discussed in the introduction have certainly greatly improved our knowledge of the group. Nonetheless, Neuroterus remains one of the most problematic genera in Cynipini. The features diagnostic of Neuroterus are (i) malar sulcus at least traceable, (ii) tarsal claws with basal lobe (except simple in N. tricolor Hartig), (iii) notauli absent, incomplete or present in the posterior $1 / 2$ or $1 / 3$ of the mesoscutum, always superficial (exceptions: $N$. anthracinus with deep and complete notauli, and $N$. tricolor with shallow and complete notauli in sexual form and deeper notauli in agamic form), (iv) lateral propodeal carinae absent (except in $N$. anthracinus and $N$. tricolor), (v) mesoscutum smooth or with weak alutaceous or coriaceous sculpture, (vi) scutellar foveae absent (except in $N$. anthracinus), (vi) transscutellar carinae absent (except in $N$. antracinus) and (vii) having a very compressed metasoma (except in $N$. antracinus). Of these diagnostic features, only the first one, i.e., presence of traceable malar sulcus, appears to be synapomorphic for the genus, a feature not found in any other genera belonging to the "Neuroterus complex", and supported by the putative synapomorphy of the lack of the medial transscutal articulation, namely, Trichagalma, Pseudoneuroterus, Latuspina,
Cerroneuroterus and Cycloneuroterus and Neuroterus.

On the other hand, the two species (N. sculpturatus sp. n. and $N$. abdominalis sp. n.) stand out among all Neuroterus species by being associated with oaks of the Cerris section. In Melika et al. (2010), all Neuroterus species described in Western Palaearctic species with galls on Cerris section belong to Cerroneuroterus. But all Cerroneuroteus have always the malar sulcus absent and the species here described have the malar sulcus more or less defined: clearly in N. abdominalis sp. n. (Fig. 2b) and present but inconspicuous in N. sculpturatus sp. n. (Fig. 2h). Therefore, $N$. sculpturatus sp. n. and $N$. abdominalis sp. n. share this putative synapomorphy of $\mathrm{Neu}$ roterus, justifying their inclusion in this genus. Then, according to our results, Neuroterus present galls also on Cerris section in Eastern Palaearctic area.

In addition, the species here described belong to Neuroterus also according to Melika et al. (2010) in having (besides characters above mentioned): head and mesosoma with sparse setae; in male antenna F1 slightly or not modified, never expanded and flattened, sometimes only curved or similar in shape to F2; notaulus if traceable in the anterior half than mesoscutum and/or mesoscutellum entirely or at least partially alutaceous or delicately coriaceous; transscutal articulation medially indistinct or absent, mesoscutum emarginate and elevated posterolaterally above dorsoaxillar area, fused with mesoscutellum; mesoscutellum without foveae, with anterior scutellar depression; prominent part of ventral spine of hypopygium always short, pointed to the apex, never more than 2.0-4.0 times as long as broad, with some long subapical setae, which never form a tuft; and hind tarsal claw usually with basal lobe. All these characters (and some mentioned above) are mentioned in the key published in Melika et al. (2010) and all of them are present in $N$. abdominalis $\mathbf{s p .} \mathbf{n}$. The only character not present in N. sculpturatus sp. n. is the shape of F1 in male; in this new species this flagellomere is expanded and flattened distally but it is clearly longer than F2 (equal or shorter in Cerroneuroterus).

Nonetheless, $N$. sculpturatus sp. n. and $N$. abdominalis sp. n. possess a number of unique 
features not found in the majority of the species of the genus. They resemble another member of the genus, $N$. tricolor, in having simple tarsal claws and superficial notauli. The presence of lateral propodeal carinae in $N$. sculpturatus sp. n. is also found in $N$. tricolor and $N$. anthracinus. Despite the apparent morphological uniqueness of $N$. antracinus, its inclusion in Neuroterus was supported by phylogenetic analyses based on morphology (Pujade-Villar et al. 1998) as well as on DNA sequence data (Stone et al. 2009). The membership of $N$. tricolor in Neuroterus is less problematic (Melika et al. 2010). Therefore, the only real peculiarities of $N$. sculpturatus $\mathbf{s p .} \mathbf{n}$. and $N$. abdominalis sp. n. with respect to the other Neuroterus species lie in the apparent sculpture present on the mesoscutum and mesoscutellum (also the mesopleuron in N. sculpturatus) (Figs 1c, 2d, g, i, 3c), which does not justify the recognition of a new genus.

The two species, $N$. abdominalis sp. n. and $N$. sculturatus sp. n., resemble each other morphologically. Neuroterus abdominalis sp. n. is probably an asexual generation, because the galls were collected in September and adults (of only the female gender) emerged in March of the following year. The galls of $N$. sculpturatus sp. n. were collected in May and adults of both sexes emerged in June of the same year. All these data suggest that they could correspond to the sexual and agamic generations of the same species, although they were collected from two locations that are more than $1,100 \mathrm{~km}$ apart. It would be especially interesting to experimentally corroborate this, because information on alternating generations of Eastern Palaearctic oak gall wasps is extremely rare.

Acknowledgements. The project was supported by the Natural Science Foundations of China (31472032 and 31071970) and Zhejiang Provincial Natural Science Foundation for Distinguished Young Scholars (LR14C040002), Science Foundation of Zhejiang A \& F University and a scholarship under the Zhejiang Association for International Exchange of Personnel.

\section{References}

Abe, Y. 2006: Taxonomic status of the genus Trichagalma (Hymenoptera: Cynipidae), with description of the bisexual generation: 288-295. — In: Ozaki, K., Yukawa, J., Ohgushi, T. \& Price, P. W. (eds), Galling arthropods and their associates. Springer, Tokyo. 308 pp.

Abe, Y., Melika, G. \& Stone, G. N. 2007: The diversity and phylogeography of cynipid gallwasps (Hymenoptera: Cynipidae) of the Oriental and Eastern Palaearctic Regions, and their associated communities. - Oriental Insects 41: 169-212.

Burks, B. D. 1979: Cynipidae: 1060-1107. — In: Krombein, K. V., Hurd, P. D., Jr., Smith, D. R. \& Burks, B. D. (eds), Catalog of Hymenoptera in America North of Mexico. Vol. 1. - Smithsonian Institution Press, Washington, D. C. 1198 pp.

Harris, R. 1979: A glossary of surface sculpturing. State of California, Department of Food and Agriculture. Occasional Papers of Entomology 28: 1-31.

Kinsey, A. C. 1923: The gall wasp genus Neuroterus (Hymenoptera). - Indiana University Studies 58: 1-150.

Liljeblad, J. \& Ronquist, F. 1998: A phylogenetic analysis of higher-level gall wasp relationships (Hymenoptera: Cynipidae). — Systematic Entomology 23: 229252.

Melika, G. 2006: Gall Wasps of Ukraine. Cynipidae. Vestnik zoologii, supplement, 21(2): 301-644.

Melika, G. \& Abrahamson, W. G. 1997: Descriptions of four new species of cynipid gall wasps of the genus Neuroterus Hartig (Hymenoptera: Cynipidae) with redescriptions of some known species from the Eastern USA. - Proceedings of the Entomological Society of Washington 99(3): 560-573.

Melika, G. \& Abrahamson, W. G. 2002: Review of the world genera of oak cynipid wasps (Hymenoptera:Cynipidae: Cynipini): 150-190. — In: Melika, G. \& Thuroczy, C. (eds), Parasitic Wasps: Evolution, Systematics, Biodiversity and Biological Control. Agroinform, Budapest. 480 pp.

Melika, G., Pujade-Villar, J., Abe, Y., Tang, C. T., Nichols, J., Wachi, N., Ide, T., Yang, M., Pénzes, Z., Csóka, G. \& Stone, G. N. 2010: Palaearctic oak gallwasps galling oaks (Quercus) in the section Cerris: re-appraisal of generic limits, with descriptions of new genera and species (Hymenoptera: Cynipidae: Cynipini). — Zootaxa 2470: 1-79.

Pujade-Villar, J., Bellido, D., Segú, G. \& Melika, G. 2001: Current state of knowledge of heterogony in Cynipidae (Hymenoptera, Cynipoidea). - Sessió Conjunta d'Entomologia de la ICHN-SCL 11(1999): 87-107.

Pujade-Villar, J., Equihua-Martinez, A., Estrada-Venegas, E. G. \& Changoyán-Garcia, C. 2009: Estado del Conocimiento de los Cynipini (Hymenoptera: Cynipidae) en México: Prespectivas de Estudio. - Neotropical Entomology 38(6): 809-821. [In Spanish.]

Pujade-Villar, J. \& Ferrer-Suay, M. 2015: Adjudicació genèrica d'espècies mexicanes d'ubicació dubtosa descrites per Kinsey i comentaris sobre la fauna mexicana (Hymenoptera: Cynipidae: Cynipini). — Butlletí de la 
Institució Catalana d'Història Natural 79: 7-14. [In Catalan.]

Pujade-Villar, J., Kovalev, O. \& Liljeblad, J. 2004: Status of Pseudoneuroterus Kinsey, 1923 and remarks on closely related genera (Hymenoptera, Cynipidae). Nouvelle Revue d'Entomologie (N. S.) 20(4): 353 360 .

Pujade-Villar, J., Ros-Farré, P. \& Arnedo, M. A. 1998: Phylogenetic position of Neuroterus anthracinus (Curtis, 1838) n. comb. (Hym., Cynipidae). — Butlletí de la Institució Catalana d'Història Natural 66: 111112.

Pujade-Villar, J \& Wang, J. 2012: A new species of the genus Trichagalma Mayr from China (Hym.: Cynipidae). - Orsis 26: 91-101.

Ronquist, F. \& Nordlander, G. 1989: Skeletal morphology of an archaic cynipoid, Ibalia rufipes (Hymenoptera: Ibaliidae). - Entomologica Scandinavica (Suppl.) 33: $1-60$.
Stone, G. N., Schönrogge, K., Atkinson, R. J. Bellido D. \& Pujade-Villar J. 2002: The population biology of oak gall wasps (Hymenoptera: Cynipidae). - Annual Review of Entomology 47: 633-668.

Stone, G. N., Hernandez-Lopez, A., Nicholls, J. A., di Pierro, E., Pujade-Villar, J, Melika, G. \& Cook, J. M. 2009: Extreme host plant conservatism during at least 20 million years of host plant pursuit by oak gallwasps. — Evolution, 63: 854-869.

Tang, C. T., Melika, G., Nicholls, J., Yang, M. M. \& Stone, G. N. 2011: A new genus of oak gallwasps, Cycloneuroterus Melika \& Tang, with the description of five new species from Taiwan (Hymenoptera: Cynipidae: Cynipini). - Zootaxa 3008: 33-62.

Tang, C. T., Sinclair, F. \& Melika, G. 2012: Anew Latuspina Monzen oak gallwasp species from Taiwan (Hymenoptera: Cynipidae: Cynipini). - Journal of Asia-Pacific Entomology 15: 573-577. 